\title{
Spatial Distribution of Carbon, Nitrogen and Phosphorus within Surface Sediments in the Lower Lancang River: Pollution Assessment Related to Dams
}

\author{
Hongjun Lu, Kaidao Fu*, Ting Dong, Wanhui Peng, Xiaorui Song, Baiyun He, Liyuan Wang \\ Institute of International Rivers and Eco-Security, Yunnan Key Laboratory of International Rivers and Trans-Boundary \\ Eco-Security, Yunnan University, Kunming, China \\ Email: *kdfu@ynu.edu.cn
}

How to cite this paper: Lu, H.J., Fu, K.D., Dong, T., Peng, W.H., Song, X.R., He, B.Y. and Wang, L.Y. (2018) Spatial Distribution of Carbon, Nitrogen and Phosphorus within Surface Sediments in the Lower Lancang River: Pollution Assessment Related to Dams. Journal of Environmental Protection, 9, 1343-1358.

https://doi.org/10.4236/jep.2018.913083

Received: November 19, 2018

Accepted: December 8, 2018

Published: December 11, 2018

Copyright $(9) 2018$ by authors and Scientific Research Publishing Inc. This work is licensed under the Creative Commons Attribution International License (CC BY 4.0).

http://creativecommons.org/licenses/by/4.0/

\begin{abstract}
Surface sediment is one of the main sources of nutrients in overlying water environments, and these can also indirectly reflect the degree of eutrophication. In this paper, the spatial distribution characteristics of total organic carbon (TOC), total nitrogen (TN) and total phosphorus (TP) in the surface sediments of 11 sections in the lower Lancang River during flood season are analyzed, as well as the distribution of phosphorus in different forms. The main sources of TOC and its correlation with TN and TP are discussed and, finally, the pollution levels of the surface sediments are evaluated. The results show that the average content of TOC in the surface sediments of the lower Lancang River is $9003.75 \mathrm{mg} / \mathrm{kg}$. The average TN content is $893.79 \mathrm{mg} / \mathrm{kg}$, while the average TP content is $521.35 \mathrm{mg} / \mathrm{kg}$. The TOC in the surface sediments of the lower Lancang River is derived mainly from algae and plankton in the river, and the TN and TP have similar sources. The total phosphorus in the surface sediments of the lower Lancang River is composed mainly of calcium-bound phosphorus (Ca-P). The evaluations of the organic pollution index and comprehensive pollution index show that the surface sediment pollution degree at the upper sections of the Nuozhadu and Jinghong Dams are more serious than those below the dams. Furthermore, the tributary sections are all slightly polluted, with the exception of the Mengyang River, which is considered moderately polluted.
\end{abstract}

\section{Keywords}

Lancang River, Surface Sediment, Nutrients, Spatial Distribution, Pollution Assessment 


\section{Introduction}

Sediment is an essential component of every river ecosystem [1] and the source of nutrient elements, such as carbon, nitrogen and phosphorus, which are of great significance to the migration and transformation of river biogenic elements. Sediment can absorb pollutants from the water and purify the overlying water environment. Conversely, however, sediment can also be a source of internal pollution [2], when the external pollution is controlled, releasing nitrogen and phosphorus, which results in eutrophication of the water. The migration and transformation of nitrogen and phosphorus with river sediments can affect the bioavailability of these nutrients in the water [3]. Furthermore, additional elements, such as calcium, aluminum and iron in the sediments, are adsorbed with phosphorus to form different patterns of phosphorus [4]. The difficulty of their release directly affects the quality of the river water environment and, consequently, the pollution status of river sediments indirectly reflects the extent of pollution in overlying water environments [5]. It is, therefore, of great scientific significance that the contents of carbon, nitrogen and phosphorus in river sediments and their spatial distribution are studied and the pollution status of sediments are evaluated, as these factors contribute substantially to the control of river eutrophication and improvement of the environmental quality of river water.

The Lancang-Mekong River is an important international river providing abundant biological resources, which is why the impact of hydropower development on the river's ecology has attracted much attention [6]. Reservoir impoundment increases the time of water body retention and has a certain interception effect on its sediment [7]. This, in turn, increases the interception of biogenic elements, such as carbon, nitrogen and phosphorus [8], and changes the biogeochemical cycle of these nutrients in the river [9]. In recent years, several scholars have investigated the distribution of sediment nutrients in water bodies such as reservoirs, rivers and lakes, in which the nutrient concentrations vary widely. Zhang et al. [10] studied the sediments of Xiangxi Bay in the Three Gorges Reservoir, where the results showed that the concentration range of TP was $800-1070 \mathrm{mg} / \mathrm{kg}$, while the concentration of TN ranged from $890-1080$ $\mathrm{mg} / \mathrm{kg}$. Varol [11] researched sediments from Tigris River and found the concentration range of TP to be $338.6-1875 \mathrm{mg} / \mathrm{kg}$, while the range of TN was 120 $3760 \mathrm{mg} / \mathrm{kg}$. Wang et al. [12] analyzed the surface sediments of Nansi Lake, indicating that the concentrations of TOC, TN and TP ranged from 0.16 to $9.06 \%, 340$ to $7680 \mathrm{mg} / \mathrm{kg}$, and 390 to $1370 \mathrm{mg} / \mathrm{kg}$, respectively. Although Chinese researchers Zhao et al. [13] studied the sediments both upstream and downstream of Manwan Dam in the lower Lancang River, recording concentration ranges for TOC, TN and TP at $0.16 \%-9.06 \%, 200-1300 \mathrm{mg} / \mathrm{kg}$ and 436.19 - $728.45 \mathrm{mg} / \mathrm{kg}$, respectively, there remains a lack of systematic focus on the carbon, nitrogen and phosphorus levels in the surface sediments of the Lancang River Basin. Therefore, this current study of the spatial distribution of carbon, nitrogen and phosphorus in the surface sediments of the lower Lancang River 
will provide valuable instructive data for the hydropower development of the Lancang River.

In this paper, four tributaries and seven mainstream control sections were selected as the key points for study, covering Nuozhadu and Jinghong Reservoirs in the lower reaches of the Lancang River during the flood season of 2018. The contents of carbon, nitrogen, phosphorus and different forms of phosphorus in the sediments were analyzed, and the spatial distribution characteristics of the concentrations of these three elements will be discussed. The pollution risks of the sediments from each of the 11 sampling sites were evaluated using the organic pollution index and the comprehensive pollution index, in order to provide a scientific basis that can inform both hydropower development and sustainable ecological protection in the lower reaches of the Lancang River.

\section{Materials and Methods}

\subsection{Study Area}

This research selected the Nuozhadu Reservoir and Jinghong Reservoir (including the waters downstream of Jinghong Dam) in the lower reaches of Lancang River as its area of study. The Nuozhadu Reservoir is located $200 \mathrm{~km}$ from the Dachaoshan Dam and below it is the Jinghong Reservoir. Construction began on the Nuozhadu Hydropower Station in 2004 and it began operations in 2012. It is the fifth cascade of two reservoirs and eight levels in the middle and lower reaches of the Lancang River. With a dam height of 261.5 meters, total installed capacity of 5.85 million kilowatts and a total storage capacity of 237.03 billion cubic meters [14]. Jinghong Hydropower Station was built in 2003 and put into operation in 2008. It is the sixth stage in the planning of the middle and lower reaches of Lancang River, with a dam height of 108 meters, total installed capacity of 1.75 million kilowatts and a total reservoir capacity of 11.39 billion cubic meters [15].

\subsection{Sampling}

Sediment samples were collected from seven mainstream sections of the lower Lancang River in July 2018 (below the Dachaoshan Dam-G1, Jinglinqiao-G2, upper the Nuozhadu Dam-G3, below the Nuozhadu Dam-G4, SimaoPort-G5, upper the Jinghong Dam-G3, and below the Jinghong Dam-G4), as well as four sections of its tributaries (the right bank of the Xiaoheijiang-Z1, the left bank of the Xiaoheijiang-Z2, Heihe-Z3, and Mengyang River-Z4), as indicated in Figure 1. Surface sediments were sampled based on Chinese reservoir hydrological survey criteria, depending on the river width, water depth and flow conditions. In order to ensure accurate measurements of the carbon, nitrogen and phosphorus contents in the surface sediments, samples of $0-5 \mathrm{~cm}$ were collected from the riverside surface without human disturbance. Approximately $1 \mathrm{~kg}$ sediment was collected at each section from three different locations. The sediment material was stored in a plastic bag and transported back to the laboratory at a low 


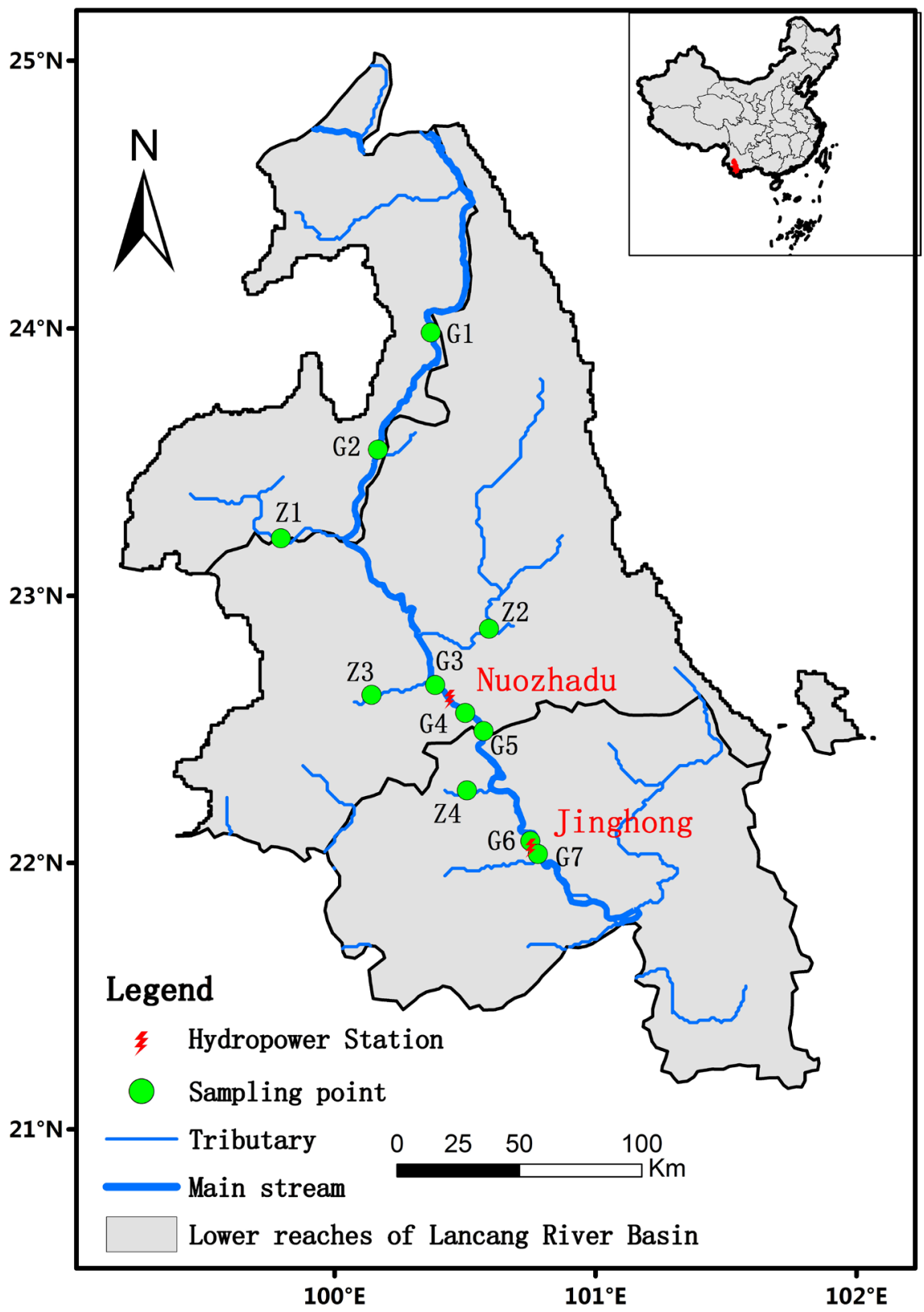

Figure 1. Schematic diagram of sampling points.

temperature. In our laboratory, the sediment was left to dry naturally, withered branches and stones were removed, and the material was then milled in an agate bowl. Finally, the sediment was sifted in 100 mesh sieves and the samples were then prepared using the inquartational method.

\subsection{Sample Determination}

TOC and TN in the sediments were determined by means of vario TOC (Total Organic Carbon) cube analysis (Elementar, Germany) and FIA-6000 multi-channel automatic flow injection analysis (Beijing Jitian Instrument Co., Ltd., China). The TP was measured by means of alkali melting-molybdenum antimony an- 
ti-spectrophotometry (HJ632-2011).

The total phosphorus in sediments can be divided into organic phosphorus (Ora-P) and inorganic phosphorus (IP), the latter of which can be further categorized into weakly adsorbed phosphorus (Ex-P), aluminum-bound phosphorus (Al-P), iron-bound phosphorus (Fe-P), occluded phosphorous (Oc-P) and calcium-bound phosphorus (Ca-P). In the sediments in this assay, the IP was measured by grading [16], as seen in Figure 2, while the content of Ora-P was calculated as the total phosphorus minus the inorganic phosphorus.

\subsection{Sediment Pollution Assessment Method}

\subsubsection{Organic Pollution Index Method}

The organic pollution index [17] is used to assess the degree of pollution by studying the contents of TOC and TN in river sediments. The formulae are described in (1) and (2), below, and the assessment criteria are outlined in Table 1.

$$
\begin{gathered}
\mathrm{ON}=\mathrm{TN} \times 95 \% \\
\mathrm{OI}=\mathrm{TOC} \times \mathrm{ON}
\end{gathered}
$$

In the above formulae, $\mathrm{ON}$ is the organic nitrogen (\%) in the sediment, $\mathrm{TN}$ is

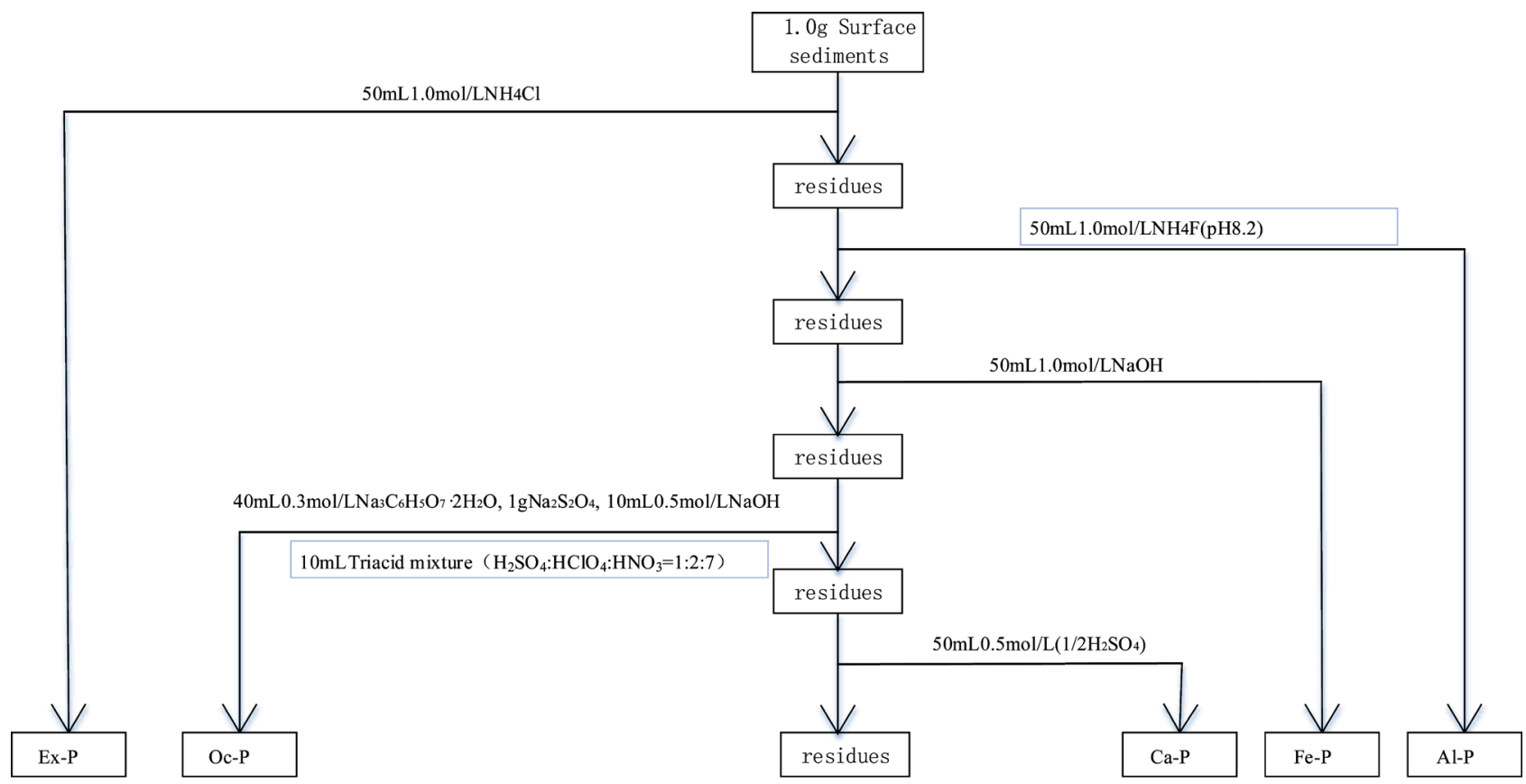

Figure 2. Flow chart for fractional extraction of inorganic phosphorus in sediments.

Table 1. Evaluation criteria for organic pollution index of sediments

\begin{tabular}{cccc}
\hline OI & ON $/ \%$ & Evaluation grade & Pollution level \\
\hline OI $<0.05$ & ON $<0.033$ & I & Cleaning \\
$0.05 \leq$ OI $<0.20$ & $0.033 \leq$ ON $<0.066$ & II & Mild pollution \\
$0.20 \leq$ OI $<0.50$ & $0.066 \leq \mathrm{ON}<0.133$ & III & Moderate pollution \\
$0.50 \leq$ OI & $0.133 \leq$ ON & IV & Severe pollution \\
\hline
\end{tabular}


the total nitrogen (\%) in the sediment, OI is the organic pollution index, and TOC is the organic carbon (\%) in the sediment.

\subsubsection{Comprehensive Pollution Index Method}

The comprehensive pollution index [18] is a method for assessing the degree of pollution by studying the contents of TP and TN in river sediments. The formulae are described in (3) and (4), below, and the assessment criteria outlined in Table 2.

$$
\begin{gathered}
S_{\mathrm{i}}=C_{\mathrm{i}} / C_{\mathrm{s}} \\
F F=\sqrt{\frac{F^{2}+F_{M A X}^{2}}{2}}
\end{gathered}
$$

In the above formulae, $S_{\mathrm{i}}$ is the single evaluation standard index, $S_{\mathrm{i}}>1$ indicates that the factor $i$ content exceeds the evaluation standard value, $C_{\mathrm{i}}$ is the measured value of factor $i(\mathrm{mg} / \mathrm{kg})$, and $C_{\mathrm{s}}$ is the evaluation standard value of factor $i(\mathrm{mg} / \mathrm{kg})$. The evaluation standard values of total nitrogen and total phosphorus are $550 \mathrm{mg} / \mathrm{kg}$ and $600 \mathrm{mg} / \mathrm{kg}$, respectively, indicating the concentrations of TN and TP in sediment that pose the lowest environmental risk [19]. $F F$ is the composite pollution index, $\mathrm{F}$ is the average of pollution index (average of $S_{T N}$ and $S_{T P}$ ), and $F_{M A X}$ is the maximum pollution index (maximum of $S_{T N}$ and $\left.S_{T P}\right)$.

\subsection{Data Processing and Analysis}

Statistics and tables of experimental data were created using Excel 2013, drawing was done using Origin 9.0 and ArcGIS 10.2, and the analysis of the significant differences in the nutrients in the surface sediments of the lower Lancang River was conducted using SPSS17.0.

\section{Results}

\subsection{Spatial Distribution of Carbon, Nitrogen and Phosphorus in Sediments}

Further to the processing and analysis of the surface sediment samples described above, the following results were ascertained: The content of TOC in the surface sediments of the mainstream of the lower reaches of the Lancang River was found to range from $6750-13,360 \mathrm{mg} / \mathrm{kg}$, with an average value of $8930.00 \mathrm{mg} / \mathrm{kg}$. TN content ranged from $626.03 \mathrm{mg} / \mathrm{kg}$ to $1220.83 \mathrm{mg} / \mathrm{kg}$, with an average

Table 2. Evaluation criteria for comprehensive pollution index of sediments

\begin{tabular}{ccc}
\hline FF & Evaluation grade & Pollution level \\
\hline $\mathrm{FF}<1.0$ & I & Cleaning \\
$1.0 \leq \mathrm{FF} \leq 1.5$ & II & Mild pollution \\
$1.5<\mathrm{FF} \leq 2.0$ & III & Moderate pollution \\
$2.0<\mathrm{FF}$ & IV & Severe pollution \\
\hline
\end{tabular}


of $909.88 \mathrm{mg} / \mathrm{kg}$, while the TP content ranged from $367.99 \mathrm{mg} / \mathrm{kg}$ to 736.13 $\mathrm{mg} / \mathrm{kg}$, with an average of $546.80 \mathrm{mg} / \mathrm{kg}$. As is evident in Figure 3, the maximum values were found at the G1 sampling point. The contents of TOC and TP in the sediments of the four main tributaries were similar, with average values of $9077.50 \mathrm{mg} / \mathrm{kg}$ and $495.90 \mathrm{mg} / \mathrm{kg}$, respectively. The maximum content of TN was $1080.52 \mathrm{mg} / \mathrm{kg}$ at the Z4 sampling point, with an average value of 877.70 $\mathrm{mg} / \mathrm{kg}$ in the tributaries. The spatial distribution of TOC, TP and TN in the sediments was similar, with the trend gradually decreasing from upstream to downstream. Nutrient concentrations at sampling points G3 and G6 were found to be significantly higher than those at G4 and G7, because of the dam impoundment and sediment retention, which have resulted in the intensified adsorption of carbon, nitrogen and phosphorus in the water were adsorbed with suspended sediment deposits. The nutrient content in the sediments of the tributaries are lower than that in the adjacent mainstream sections. The content of
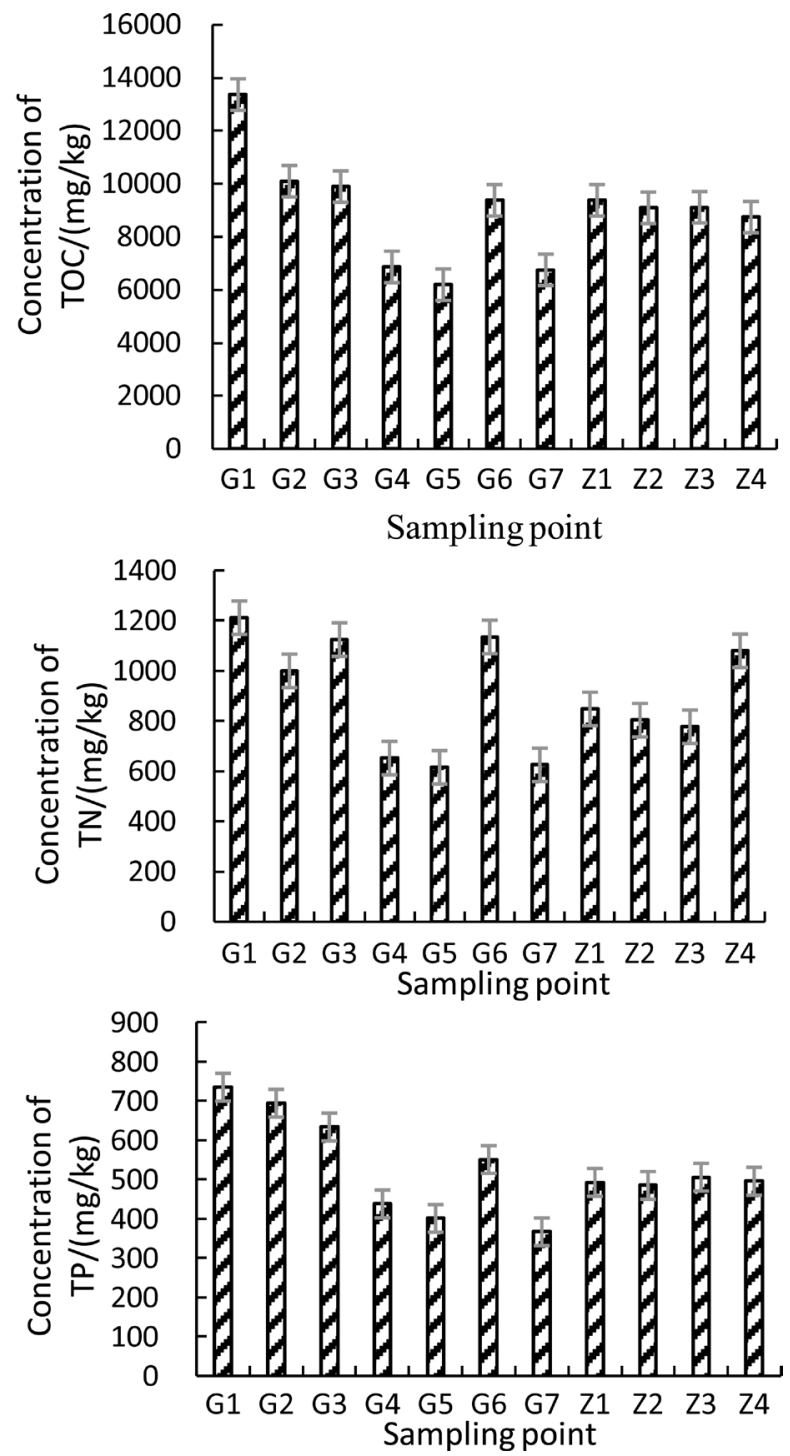

Figure 3. Spatial distribution of TOC, TN and TP in sediments. 
TN in the sediments from the Z4 sampling site, was significantly higher than those of the other three tributaries, possibly because of its location near the village of Dahe, which is surrounded by farmland and dense banana forests. The spatial distribution findings suggest that the concentrations of TOC, TN and TP in the surface sediments of the lower reaches of Lancang River are influenced by both human activities and dam interception.

\subsection{Sources of TOC in Sediments and Correlation with TN and TP}

The carbon-to-nitrogen $(\mathrm{C} / \mathrm{N})$ value in sediments can indirectly reflect their source of TOC [20]. Previous studies have ascertained that the $\mathrm{C} / \mathrm{N}$ values of higher plants, aquatic organisms, plankton and algae range from 14 to $23,2.8$ to 3.4, 6 to 13, and 5 to 14, respectively [21]. As shown in Figure 4, the $\mathrm{C} / \mathrm{N}$ values in the surface sediments of the mainstream of the lower Lancang River were found in this study to be between 8.20 and 10.94, with an average value of 9.86 , and those of the tributary sediments to be between 8.05 and 11.63 , with an average value of 10.48. The TOC in the surface sediments of both the mainstream and tributaries is derived mainly from algae and plankton, suggesting that the release of nutrients from the surface sediments of the lower reaches of the Lancang River results in the continuous propagation of algae and plankton in the overlying water environment.

The correlation analysis of TOC, TN and TP concentrations in the sampled sediments (Table 3 ) showed that there were significant differences between the concentrations of carbon, nitrogen and phosphorus $(P<0.01, n=11)$. The similar sources of the three nutrients in the surface sediments of the dry tributaries of the lower Lancang River suggest an accumulation of total nitrogen and phosphorus, mainly from organic matter in the sediments of the lower Lancang River basin, which enter the sediments through the deposition of plankton and algal residues.

\subsection{Speciation and Distribution of Phosphorus Adsorbed by Surface Sediments}

The distribution patterns of phosphorus in the surface sediments of the mainstream

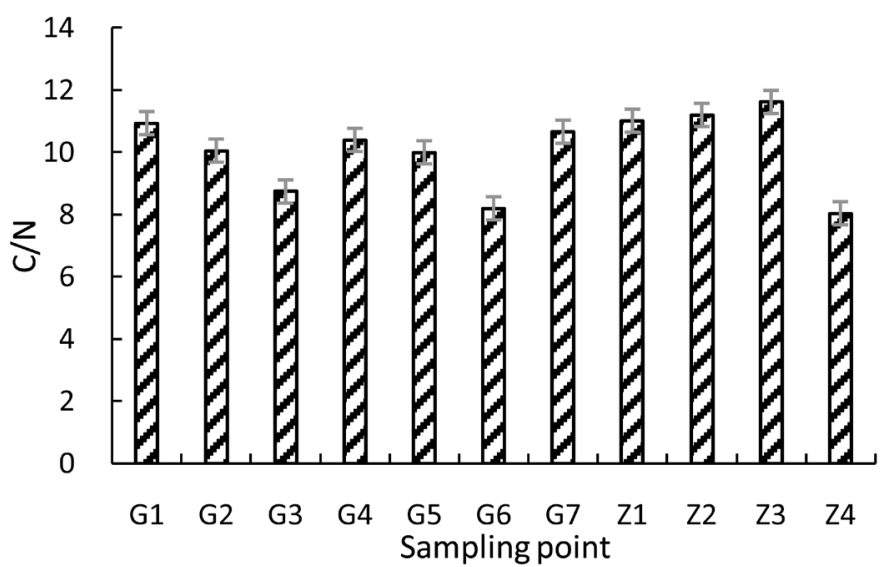

Figure 4. Spatial distribution of $\mathrm{C} / \mathrm{N}$ value in sediments. 
Table 3. Correlation analysis of indicators in surface sediments of 11 sections.

\begin{tabular}{cccccccccc}
\hline Indicators & TOC & TN & TP & Ex-P & Al-P & Fe-P & O-P & Ca-P & Ora-P \\
\hline TOC & 1 & & & & & & & & \\
TN & $0.828^{* *}$ & 1 & & & & & & & \\
TP & $0.912^{* *}$ & $0.830^{* *}$ & 1 & & & & & & \\
Ex-P & -0.078 & -0.213 & -0.145 & 1 & & & & & \\
Al-P & $0.698^{*}$ & $0.641^{*}$ & 0.506 & 0.076 & 1 & & & \\
Fe-P & $0.809^{* *}$ & $0.647^{*}$ & $0.806^{* *}$ & -0.384 & 0.222 & 1 & & & \\
O-P & 0.570 & 0.340 & $0.653^{*}$ & -0.005 & 0.491 & 0.287 & 1 & & \\
Ca-P & $0.866^{* *}$ & $0.842^{* *}$ & $0.955^{* *}$ & -0.054 & 0.481 & $0.771^{* *}$ & 0.456 & 1 & \\
Ora-P & 0.591 & $0.719^{*}$ & $0.807^{* *}$ & -0.390 & 0.032 & $0.792^{* *}$ & 0.279 & $0.798^{* *}$ & 1 \\
\hline
\end{tabular}

Note: ${ }^{*}$ extremely significant level of $\alpha=0.01,{ }^{*}$ significant level of $\alpha=0.05$.

and tributaries of the lower reaches of the Lancang River were found to be consistent, as seen in Figure 5. TP was notably dominated by IP, accounting for $80.74 \%-89.58 \%$ and $87.00 \%-89.10 \%$, respectively, while Ora-P accounts for a small proportion. Furthermore, the proportion of Ca-P in IP was the highest, exceeding 50\%, followed by O-P, Fe-P, Al-P and Ex-P. The results indicated that there is a significant amount of inert phosphorus in the surface sediments, which is not released easily and, thus, has less impact on the overlying water environment. However, when the $\mathrm{pH}$ in the water drops sharply, Ca-P can be released in large quantities and become an endogenous source of pollution in rivers [22].

Ex-P is the phosphorus most easily utilized by river organisms [23], with concentrations ranging from 1.50 to $6.05 \mathrm{mg} / \mathrm{kg}$, and an average of $3.34 \mathrm{mg} / \mathrm{kg}$. The maximum concentration of Ex-P was found at the G7 sampling point, accounting for 1.64\%. Al-P and Fe-P are bioavailable phosphori [23]. Their concentrations ranged from 19.43 to $60.19 \mathrm{mg} / \mathrm{kg}$ and 31.82 to $82.89 \mathrm{mg} / \mathrm{kg}$, respectively, with average values of 34.04 and $57.68 \mathrm{mg} / \mathrm{kg}$, respectively. The maximum values appeared at the G1 sampling point, accounting for $8.18 \%$ and $11.26 \%$, respectively. Oc-P is a biologically unavailable phosphorus [24], with concentrations ranging from 67.69 to $168.55 \mathrm{mg} / \mathrm{kg}$, an average of $120.64 \mathrm{mg} / \mathrm{kg}$, and the maximum concentration occurring at the G2 sampling point, accounting for $24.24 \%$. $\mathrm{Ca}-\mathrm{P}$ is a kind of phosphorus not easily utilized by organisms [25]. Its concentration was found to range from 162.86 to $351.56 \mathrm{mg} / \mathrm{kg}$, with an average of $240.40 \mathrm{mg} / \mathrm{kg}$, and the maximum value appearing at the G1 sampling point, accounting for $47.76 \%$. Lastly, Ora-P, which can be partially utilized by organisms [26], was found in concentrations ranging from 38.34 to $122.28 \mathrm{mg} / \mathrm{kg}$, with an average of $72.18 \mathrm{mg} / \mathrm{kg}$. The maximum value was recorded at the G3 sampling point, accounting for $19.26 \%$.

Correlation analysis (Table 3) revealed a significant difference between the concentrations of Ca-P, Fe-P and Ora-P in the surface sediments of the mainstream and tributaries of the lower Lancang River $(\mathrm{P}<0.01, \mathrm{n}=11)$, although 

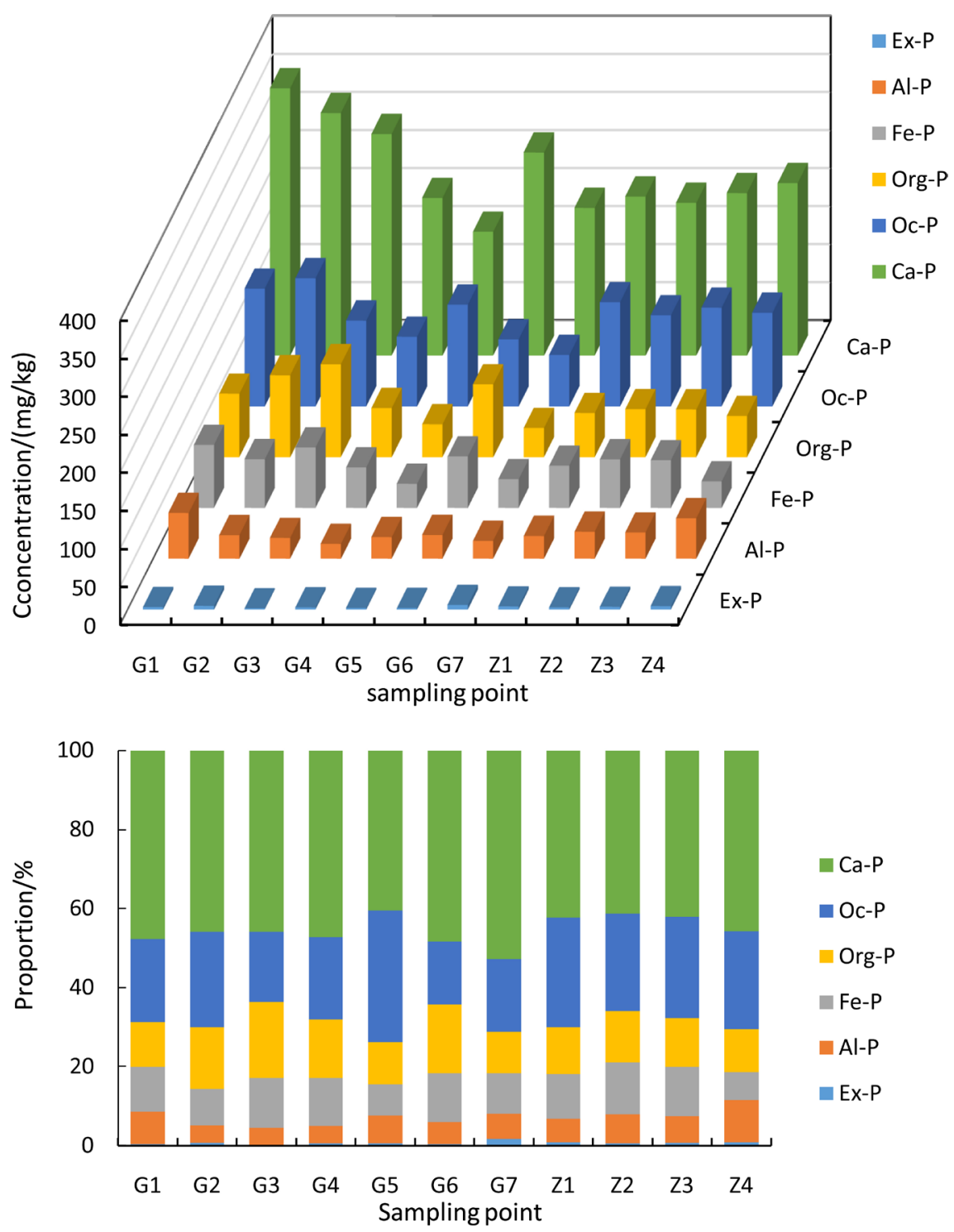

Figure 5. Distribution and proportion of phosphorus in sediments.

there were no significant differences between the other forms of phosphorus. The results indicate that there is a certain coupling relationship between Ca-P, Fe-P and Ora-P, because Ca-P and Fe-P in surface sediments have a strong adsorption in organic debris.

\subsection{Evaluation of Sediment Pollution}

\subsubsection{Organic Pollution Index}

First, the organic pollution index was used in the process of evaluation, in which the measured concentrations of TOC and TN in sediments of the above mentioned 11 sections in the lower reaches of Lancang River were substituted into the formulae (1) and (2), and the organic pollution indices and grades were calculated, as shown in Table 4.

The range of organic pollution index in the surface sediments of the mainstream 
Table 4. Assessment of sediment pollution in the lower reaches of the Lancang River.

\begin{tabular}{cccccc}
\hline \multicolumn{2}{c}{ Sampling point } & OI & Evaluation grade & FF & Evaluation grade \\
\hline \multirow{5}{*}{ Mainstream } & G1 & 0.155 & II & 1.99 & III \\
& G2 & 0.096 & II & 1.67 & III \\
& G3 & 0.106 & II & 1.82 & III \\
& G5 & 0.043 & I & 1.09 & II \\
& G6 & 0.036 & I & 1.02 & II \\
& G7 & 0.041 & II & 1.81 & III \\
& Z1 & 0.076 & I & 1.02 & II \\
Tributary & Z2 & 0.070 & II & 1.39 & II \\
& Z3 & 0.068 & II & 1.32 & II \\
& Z4 & 0.090 & II & 1.29 & II \\
\hline
\end{tabular}

of the lower Lancang River was determined to be $0.036-0.155$, with an average value of 0.083 , while that of the tributaries ranged from 0.068 to 0.090 , with an average value of 0.076 . The evaluation grade of the surface sediments in the mainstream is I - II. Among the sampled areas, four sections, namely G1, G2, G3 and G6, accounting for $57.14 \%$ of the total samples, were found to be mildly polluted, while the remaining three sections is regarded as cleaning. However, the four tributaries are all slightly polluted, and the pollution levels of G3 and G6 are obviously higher than those of G4 and G7 respectively.

\subsubsection{Comprehensive Pollution Index Evaluation}

According to the method of comprehensive pollution index evaluation, the measured concentrations of TP and TN in the sediments were substituted into formulae (3) and (4), and the comprehensive pollution indices and grades were calculated, as shown in Table 4.

The range of the comprehensive pollution index of the surface sediments in the mainstream of the lower Lancang River was found to be $1.02-1.99$, with an average value of 1.49 , while that of the tributaries ranged from 1.29 to 1.71 , with an average value of 1.43. The evaluation grade of surface sediments in the mainstream is II - III. Four of the sampling sections, namely G1, G2, G3 and G6, were found to be moderately polluted, accounting for $57.14 \%$ of the total sections, and the other three sections are mild polluted. Of the tributaries, Z4 is moderately polluted, while the other sections are mildly polluted. Consistent with the organic pollution index, the pollution levels of G3 and G6 are obviously higher than those of G4 and G7 respectively.

\section{Discussion}

The two-reservoir eight-level hydropower stations in the middle and lower reaches of Lancang River have been put into operation one after another. The 
development of hydropower produces clean energy and brings economic benefits, but it also leads to river fragmentation, disrupts the normal basic functions of the river ecosystem (such as material circulation, information transmission and energy flow) and, ultimately, destroys the ecological environment [27]. This work extended from the Nuozhadu Reservoir to the Jinghong Reservoir in the lower reaches of the Yunnan section of the Lancang River. These are particularly significant because the Nuozhadu Reservoir has the largest storage and installed capacities of the eight, while the Jinghong is last reservoir before the river flushes out of China to southeastern Asia. It, therefore, represents the final area of control before the Lancang River delivers its nutrients to the lower Mekong River, but the cascade dams slow the flow of water in the reservoirs, depositing suspended sediment-adsorbed nutrients, and reducing nitrogen and phosphorus in the lower reaches of the dams [28]. The results of this study show the average content of TOC, TN and TP in the surface sediments of the lower Lancang River to be $0.675 \%-1.336 \%, 0.063 \%-0.122 \%$ and $367.99-736.13 \mathrm{mg} / \mathrm{kg}$, respectively. However, the average content of TOC, TN and TP in the surface sediments of the mainstream of the Three Gorges Reservoir, on the Yangtze River, are 0.545\% $-0.893 \%, 0.203 \%-0.362 \%$ and $678.20-928.60 \mathrm{mg} / \mathrm{kg}$, respectively [29], which indicates that the average content of TN and TP in the surface sediments of the mainstream in the Three Gorges Reservoir is higher than that of the Nuozhadu and Jinghong Reservoirs, while the average content of TOC is lower. Li [30] studied the temporal and spatial distribution of nitrogen and phosphorus in Nuozhadu Reservoir water, with results indicating that the concentration of TP in the water upper the dam is 1.43 times higher than in the water below the dam in the flood season, but 2.32 times higher in the dry season. The results of our study show that TOC, TN and TP in the surface sediments upper the Nuozhadu Dam are 1.44, 1.72 and 1.45 times higher, respectively, than those found below the dam, and TOC, TN and TP in the surface sediments upper the Jinghong Dam are 1.39, 1.81 and 1.50 times higher, respectively, than those below it. These findings indicate that the dams have obvious interception effects on the nutrients in water and sediment, which is consistent with investigations into the nutrients found in Manwan Reservoir, upstream of Nuozhadu Reservoir [13].

The sources of TOC in sediments are both endogenous and exogenous. According to the $\mathrm{C} / \mathrm{N}$ value analysis, the TOC in surface sediments of the Nuozhadu and Jinghong Reservoirs is derived mainly from algae and plankton, but when Zhao et al. [31] studied the source of organic matter in the sediments of Manwan and Dachaoshan Reservoirs of the Lancang River, results indicated that the organic matter consisted mainly of terrestrial sources, including plant, soil and granular organic matter. Based on the research under taken by Zhang et al. [32], TOC derives mainly from endogenous sources with $\mathrm{C} / \mathrm{N}$ less than 10 , while its exogenous sources measure more than 10 . When the ratio of $\mathrm{C} / \mathrm{N}$ is approximately equal to 10 , it reaches a balance between the endogenous and exogenous sources. However, the average value of $\mathrm{C} / \mathrm{N}$ in the surface sediments of the 
mainstream in the lower Lancang River is 9.86, and the average value of $\mathrm{C} / \mathrm{N}$ in the tributaries is 10.48 , which shows that the source of TOC in the surface sediments of the mainstream of the lower Lancang River is mainly endogenous, while the tributaries are mainly exogenous. This also indicates that the tributaries have unique geographical conditions and are greatly disturbed by human activities.

The chemical forms of phosphorus in sediment have an important effect on its release. Liu et al. [33] studied the distribution of phosphorus speciation in the sediments of the Xiaowan, Manwan and Dachaoshan Reservoirs. There, the highest content of calcium-bound phosphorus (HCl-P) was $49.69 \%$ in the Manwan Reservoir, and the highest content of metal oxide-bound phosphorus (NaOH-P) was $57.21 \%$ and $55.19 \%$ in Xiaowan and Dachaoshan Reservoirs, respectively. The bioavailable phosphorus content in the Xiaowan and Dachaoshan Reservoirs was higher, as was the release rate of phosphorus in the sediments. Pan et al. [34] also studied the distribution of different forms of phosphorus in the sediments of the Three Gorges Reservoir, finding that the TP was mainly composed of IP, with OP accounting for a small proportion. The IP was mainly composed of Ca-P, with Fe/Al-P accounting for relatively small portion. This current study found that the total phosphorus in the surface sediments of the lower reaches of the Lancang River comprises mainly inorganic phosphorus (IP). Calcium-bound phosphorus (Ca-P) accounts for the highest proportion in the IP, with smaller amounts of iron-bound phosphorus (Fe-P), aluminum-bound phosphorus (Al-P) and weakly adsorbed phosphorus (Ex-P). Moreover, Ca-P is notably difficult to dissolve and released usually under acidic conditions, while the lower reaches of the Lancang River show weak alkalinity all year round. Therefore, the potential risk of phosphorus release from the surface sediments of Nuozhadu and Jinghong Reservoirs of Lancang River to overlying water is small, which is consistent with the high content of Ca-P and low risk of release in the Manwan and Three Gorges reservoirs.

In this paper, the contents of carbon, nitrogen, and different forms of phosphorus in the surface sediments of 11 sections in the lower reaches of Lancang River were analyzed, and the pollution degree of nutrients in sediments evaluated, providing a scientific basis for the monitoring of nutrient release from surface sediments and eutrophication control of the watershed in the river. In view of the small number of sampling points selected in the Nuozhadu and Jinghong Reservoir areas, the study of the distribution of nutrients in sediments and the assessment of sediment pollution should be extended by increasing the sampling points. In addition, the pollution level of surface sediments should be evaluated comprehensively by combining the characteristics of sediment size and mineral composition.

\section{Conclusion}

The spatial distribution of TOC, TN and TP concentrations in the surface sedi- 
ments of the mainstream of the lower Lancang River is comparatively regular, showing a gradually decreasing trend from the upstream to the downstream, with the maximum values appearing in the Dachaoshan Dam. The spatial differences of TOC and TP in the tributaries were not significant, while the content of TN in the Mengyang River is higher than that in the other three tributaries. The TOC in the surface sediments was found to be mainly derived from algae and plankton, and the TN and TP have similar sources. The distribution patterns of phosphorus in the surface sediments are consistent. IP is the main form of TP, accounting for more than $80 \%$, and $\mathrm{Ca}-\mathrm{P}$ accounts for the highest proportion in the IP. Furthermore, there is homology between the three forms of Ca-P, Fe-P and Ora-P. Finally, the two evaluation methods show that the surface sediment pollution degree at the upper sections of the Nuozhadu and Jinghong Dams is higher than that below the Dams.

\section{Conflicts of Interest}

The authors declare no conflicts of interest regarding the publication of this paper.

\section{References}

[1] Wang, P., Lu, S.Y., Wang, D.W., Xu, M.S., Gan, S. and Jin, X.C. (2012) Nitrogen, Phosphorous and Organic Matter Spatial Distribution Characteristics and Their Pollution Status Evaluation of Sediments Nutrients in Lakeside Zones of Taihu Lake. China Environmental Science, 32, 703-709.

[2] Boström, B., Persson, G. and Broberg, B. (1988) Bioavailability of Different Phosphorus Forms in Freshwater Systems. Hydrobiologia, 170, 133-155.

https://doi.org/10.1007/BF00024902

[3] Yin, A.J., Wu, P.B., Zhou, H.P. and Gao, C. (2015) Forms and Distribution of Phosphorus in Qinhuai River Sediments along an Urbanization Gradient. Acta Scientiae Circumstantiae, 35, 1366-1373.

[4] Graca, B. and Bolałek, J. (1998) Forms of Phosphorus in Sediments from the Gulf of Gdańsk. Applied Geochemistry, 13, 319-327. https://doi.org/10.1016/S0883-2927(97)00101-7

[5] Yu, H., Zhang, W.B., Lu, S.Y., Yan, S.W., Hu, R.J., Chen, L., Zhang, L.L. and Yu, J.P. (2010) Spatial Distribution Characteristics of Surface Sediments Nutrients in Lake Hongze and Their Pollution Status Evaluation. Environmental Science, 31, 961-968.

[6] Chen, L.-H. and He, D.M. (2000) The Ecological Impacts of Hydropower Cascade Development in Lancang-Mekong River. Acta Geographica Sinica, 577-586.

[7] Fu, K.D., He, D.M., Chen, W., Ye, C.Q. and Li, Y.G. (2007) Impacts of Dam Constructions on the Annual Distribution of Sediment in Lancang-Mekong River Basin. Acta Geographica Sinica, 62, 14-21.

[8] Ran, X.B., Yu, Z.G., Yao, Q.Z., Chen, H.T., Mi, T.Z., and Yao, P. (2009) Advances in Nutrient Retention of Dams on River. Journal of Lake Sciences, 21, 614-622. https://doi.org/10.18307/2009.0502

[9] Lancelot, C., Martin, J.M., Panin, N. and Zaitsev, Y. (2002) The North-Western Black Sea: A Pilot Site to Understand the Complex Interaction between Human Activities and the Coastal Environment. Estuarine Coastal and Shelf Science, 54, 
279-283. https://doi.org/10.1006/ecss.2000.0647

[10] Zhang, M., Xu, Y.Y., Shao, M.L. and Cai, Q.H. (2009) Spatiotemporal Distribution of Total Nitrogen and Total Phosphorus in Sediments of Xiangxi Bay, Three Gorges Reservoir. The Journal of Applied Ecology, 20, 2799-2805.

[11] Varol, M. (2013) Temporal and Spatial Dynamics of Nitrogen and Phosphorus in Surface Water and Sediments of a Transboundary River Located in the Semi-Arid Region of Turkey. Catena, 100, 1-9. https://doi.org/10.1016/j.catena.2012.08.003

[12] Wang, L.F., Xia, J., Yu, J.J., Yang, L.Y., Zhan, C.S., Qiao, Y.F. and Lu, H.W. (2017) Spatial Variation, Pollution Assessment and Source Identification of Major $\mathrm{Nu}$ trients in Surface Sediments of Nansi Lake, China. Water, 9, 444. https://doi.org/10.3390/w9060444

[13] Zhao, C., Dong, S.K., Liu, S.L., Sylvie, I., Li, J.P., Liu, Q. and An, N.N. (2014) Distribution and Environmental Risk Assessment of Heavy Metals and Nutrients in Sediments of Upstream and Downstream of Manwan Dam. Acta Scientiae Circumstantiae, 34, 2417-2425.

[14] Niu, J.C., Lu, L.X. and Luo, Y.P. (2015) Research on Rock Anchor Beam Excavation Technology of LANCANG river Nuozhadu Hydropower Station Underground Powerhouse in Yunnan Province. Journal of Yellow River Conservancy Technical Institute, 27, 12-16.

[15] Liu, J.T. (2008) Hydropower Development on Lancang River and Design of the Jinghong Hydropower Station. Water Power, 34, 28-31.

[16] Bao, S.D. (2000) Soil Agrochemical Analysis. 3rd Edition, China Agriculture Press, Beijing. (In Chinese)

[17] Sui, G.R. (1996) Statement and Evaluation of Organic Matter, Total Nitrogen and Total Phosphate in Surface Layer Sediments in Taihu Lake. Journal of Lake Science, 8, 319-324. https://doi.org/10.18307/1996.0405

[18] Yang, Y., Liu, Q.G., Hu, Z.J., Zhang, Y.M. and Gao, Y.X. (2014) Spatial Distribution of Sediment Carbon, Nitrogen and Phosphorus and Pollution Evaluation of Sediment in Taihu Lake Basin. Acta Scientiae Circumstantiae, 34, 3057-3064.

[19] Yue, W.Z., Huang, X.P. and Sun, C.C. (2007) Distribution and Pollution of Nitrogen and Phosphorus in Surface Sediments from the Pearl River Estuary. Oceanologia et Limnologia Sinica, 38, 111-117.

[20] Volvoikar, S.P., Nayak, G.N., Mazumdar, A. and Peketi, A. (2014) Reconstruction of Depositional Environment of a Tropical Estuary and Response of $\delta 13$ Corg and TOC/TN Signatures to Changing Environmental Conditions. Estuarine, Coastal and Shelf Science, 139, 137-147. https://doi.org/10.1016/j.ecss.2014.01.001

[21] Lu, S.Y., Xu, M.S., Jin, X.C., Huang, G.Z. and Hu, W. (2012) Pollution Characteristics and Evaluation of Nitrogen, Phosphorus and Organic Matter in Surface Sediments of Lake Changshouhu in Chongqing, China. Environmental Science, 33, 393-398.

[22] Kaiserli, A., Voutsa, D. and Samara, C. (2002) Phosphorus Fractionation in Lake Sediments-Lakes Volvi and Koronia, N. Greece. Chemosphere, 46, 1147-1155. https://doi.org/10.1016/S0045-6535(01)00242-9

[23] Xu, C.X., Yuan, J., Wang, Y.P., Wang, S.M. and Dai, A.F. (2011) Speciation and Release Mechanism of Phosphorus in Sediments and Analysis Methods for Sequential Extraction. Rock and Mineral Analysis, 30, 785-794.

[24] Filippelli, G.M. and Delaney, M.L. (1996) Phosphorus Geochemistry of Equatorial Pacific Sediments. Geochimica Cosmochimica Acta, 60, 1479-1495. 
https://doi.org/10.1016/0016-7037(96)00042-7

[25] Howarth, R. (1998) Forms and Availability of Sediment Phosphorus in Carbonate Sand of Bermuda Seagrass Beds. Limnology and Oceanography, 43, 799-810. https://doi.org/10.4319/lo.1998.43.5.0799

[26] Li, R.F., Tan, W.B., Gao, R.T., Huang, C.H., Zhang, H. and Li, D. (2018) Distribution Characteristics of Organic Matter, Nitrogen and Phosphorus in Sediments of Xiao River. Journal of Environmental Engineering Technology, 8, 241-247.

[27] Gowan, C., Stephenson, K. and Shabman, L. (2006) The Role of Ecosystem Valuation in Environmental Decision Making: Hydropower Relicensing and Dam Removal on the Elwha River. Ecological Economics, 56, 508-523. https://doi.org/10.1016/j.ecolecon.2005.03.018

[28] Qian, H.J., Gao, Y., Cao, M., Fu, J.N., Ma, J. and Wang, F.S. (2015) Impacts on Geochemical Phases of Nitrogen and Phosphorus in Sediments of Xinanjiang River by River Impounding. Journal of Shanghai University, 21, 72-80.

[29] Zhou, H.H., Qiu, G.S., Zhai, W.Y., Liu, Y. B. and Lan, J. (2017) Evaluation of Temporal and Spatial Variation Characteristics of Nutrients in Surface Sediment in the Three Gorges Reservoir Area. Environmental Science, 38, 5020-5031.

[30] Li, M.Y. (2017) Response of Spatial-Temporal Variation of Nitrogen and Phosphorus to Reservoir Construction in the Lower Reaches of the Lancang River. Master Dissertation, Yunnan University, Kunming. (In Chinese)

[31] Zhao, C., Dong, S., Liu, S., An, N., Sylvie, I., Zhao, H., Liu, Q. and Wu, X. (2018) Preliminary Study on the Effect of Cascade Dams on Organic Matter Sources of Sediments in the Middle Langcang-Mekong River. Journal of Soils and Sediments, 18, 297-308. https://doi.org/10.1007/s11368-017-1790-5

[32] Zhang, Z., Lv, Y., Zhang, W., Zhang, Y., Sun, C. and Marhaba, T. (2015) Phosphorus, Organic Matter and Nitrogen Distribution Characteristics of the Surface Sediments in Nansi Lake, China. Environmental Earth Sciences, 73, 5669-5675. https://doi.org/10.1007/s12665-014-3821-5

[33] Liu, Q., Liu, S., Zhao, H., Deng, L., Wang, C., Zhao, Q. and Dong, S. (2015) The Phosphorus Speciations in the Sediments up- and down-Stream of Cascade Dams along the Middle Lancang River. Chemosphere, 120, 653-659. https://doi.org/10.1016/j.chemosphere.2014.10.012

[34] Pan, T.T., Zhang, X., Yuan, Z.J., Song, H.Y., Zhu, K.X., Bi, Y.H. and Hu, Z.Y. (2016) Spatio-Temporal Distribution Characteristics of Different Phosphorus Forms in Sediments from the Three Gorges Reservoir. Acta Scientiae Circumstantiae, 36, 2968-2973. 